\title{
Respostas de Cultivares de Soja Transgênica e Controle de Plantas daninhas em FunÇão de Épocas de Aplicação e Formulações DE GlYPHOSATE ${ }^{1}$
}

\author{
Performance of Transgenic Soybean Cultivars and Weed Control in function of Application \\ Times and Glyphosate Formulations
}

\begin{abstract}
AGOSTINETTO, D. ${ }^{2}$, DAL MAGRO, T. ${ }^{3}$, GALON, L. ${ }^{4}$, MORAES, P.V.D. ${ }^{3}$ e TIRONI, S.P. ${ }^{5}$
RESUMO - Objetivou-se com este trabalho avaliar a seletividade e os componentes da produtividade de grãos de cultivares de soja transgênica e o controle de plantas daninhas, em função de épocas de aplicação e formulações do herbicida glyphosate. Foi conduzido experimento a campo em condições de várzea no Centro Agropecuário da Palma (CAP), da UFPel, durante a estação de crescimento 2005/06. O delineamento experimental utilizado foi de blocos completos ao acaso, arranjados em parcelas subsubdivididas, com quatro repetições. Nas parcelas alocaram-se os cultivares de soja Roundup Ready - RR (BRS 244RR, MSOY 7979RR e não registrada-NR); nas subparcelas, as épocas de aplicação do herbicida (20, 35 e 50 dias após a emergência); e nas subsubparcelas, as formulações de glyphosate (sal de isopropilamina - Roundup Ready ${ }^{\circledast}$ ou Roundup Transorb ${ }^{\circledast}$, sal de amônio - Roundup $\mathrm{WG}^{\circledast}$ e sal potássico - Zapp $\left.\mathrm{Qi}^{\circledR}\right)$ na dose de $720 \mathrm{~g}$ e.a. ha ${ }^{-1}$ e testemunha infestada. As variáveis avaliadas foram toxicidade dos herbicidas à cultura, controle das plantas daninhas, número de vagens e grãos por planta, massa e produtividade de grãos. O herbicida glyphosate, nas formulações testadas, foi seletivo aos cultivares de soja RR. Em geral, a melhor formulação para controle das plantas daninhas beldroega, caruru, papuã, capim-arroz e gramaseda foi o Roundup $\mathrm{WG}^{\circledR}$. A aplicação nos estádios iniciais de desenvolvimento da cultura proporcionou melhor controle das plantas daninhas. A produtividade de grãos variou entre cultivares de soja, não diferiu entre as formulações do herbicida glyphosate e foi superior quando a aplicação foi feita nos estádios tardios de desenvolvimento da cultura.
\end{abstract}

Palavras-chave: Glycine max, cultivo de soja em várzea, soja RR.

\begin{abstract}
This work aimed to evaluate selectivity and yield components of transgenic soybean cultivars and weed control in function of application times and glyphosate formulations. The experiment was carried out at Palma Agriculture Center (CAP/UFPel) during the 2005/2006 growing season and arranged in a randomized complete block design in split-split plots, with four replications. Roundup Ready (RR) soybean cultivars were allocated in the plots (BRS 244RR, MSOY 7979RR and $N R$, not registered ones); application times (20, 35 and 50 days after emergence) were allocated in the split-plots; and the glyphosate formulations (isopropylamine salt - Roundup Ready ${ }^{\circledR}$ or Roundup Transorb ${ }^{\circledR}$, ammonium salt - Roundup $W G^{\circledR}$ and potassium salt-Zapp Qi $\left.{ }^{\circledR}\right)$ at the rate of $720 \mathrm{~g}$ a.e. ha $^{-1}$ and infested ckeck were allocated in the split-split plots. The yield parameters evaluated were culture herbicide phytotoxicity, weed control, number of green beans and grains per plant, grain weight and grain yield. The herbicide glyphosate in the tested formulations was selective to the tested soybean cultivars. In general, the best weed control formulation was Roundup WG ${ }^{\circledR}$. At the initial development of the culture, herbicide application provided better control of purslane, redroot pigweed, alexandergrass, barnyardgrass and bermudagrass. Grain yield varied among soybean cultivars but it did not differ among the glyphosate formulations, being higher when the application was accomplished at the late stages of culture development.
\end{abstract}

Keywords: Glycine max, meadow soybean cultivation, RR soybean.

1 Recebido para publicação em 11.9.2008 e na forma revisada em 13.11.2009.

2 Professor da Faculdade de Agronomia Eliseu Maciel (FAEM) da Universidade Federal de Pelotas - UFPel, C.P. 354, $96010-900$ Capão do Leão-RS, <dirceu_agostinetto@ufpel.tche.br $>$, Bolsista do CNPq; ${ }^{3}$ Eng ${ }^{\circ}$ Agr ${ }^{\circ}$. , aluno do Programa de Pós-Graduação em Fitossanidade-UFPel; <taisadm@yahoo.com.br>e<pvdmoraes@ig.com.br>; ${ }^{4}$ Eng ${ }^{\circ}$ Agr ${ }^{\circ}$., D.Sc., Pós-Doutorando -Dep. de Fitotecnia, Universidade Federal de Viçosa - DFT/UFV, Bolsista PDJ/CNPq, Avenida P.H. Rolfs, s/n, Campus Universitário, 36570-000 ViçosaMG, <leandro.galon@ufv.br>; ${ }^{5}$ Eng $^{\underline{0}}$ Agr ${ }^{0}$., M.Sc., Doutorando - DFT/UFV, Bolsista CAPES, <siumar.tironi@gmail.com>

Planta Daninha, Viçosa-MG, v. 27, n. 4, p. 739-746, 2009 


\section{INTRODUÇÃO}

O cultivo de soja em áreas de várzea é uma alternativa de produção de grãos, em rotação com o arroz irrigado. Vários trabalhos têm sido realizados com o objetivo de buscar alternativas de cultivo em áreas orizícolas irrigadas por inundação (Ferreira et al., 2001; Galon et al., 2007). Os resultados demonstram que a soja pode tolerar períodos longos de inundação, porém essa tolerância varia entre cultivares e com as condições edafoclimáticas.

A soja transgênica (Roundup Ready - $R^{\circledR}$ ) resistente ao herbicida glyphosate representa uma inovação tecnológica no controle de plantas daninhas (Reddy \& Zablotowics, 2003). A produção comercial iniciou-se em 1997 na Argentina e, anos depois, os cultivares RR, mesmo ilegalmente, foram cultivados no Rio Grande do Sul e, em seguida, difundiram-se para outros Estados brasileiros (Fronza \& Zito, 2005).

O mecanismo de ação do glyphosate é representado pela inibição da enzima 5enolpiruvilchiquimato-3-fosfato sintase, a qual impede a sintese dos aminoácidos aromáticos fenilalanina, tirosina e triptofano, essenciais para a sintese de proteínas e divisão celular nas plantas (Rodrigues \& Almeida, 2005). Atualmente encontram-se no mercado, sendo usados no Brasil para o controle de plantas daninhas em lavouras de soja transgênica, o sal de isopropilamina (Roundup Ready ${ }^{\circledR}$ e Roundup Transorb ${ }^{\circledR}$ ), sal de amônio (Roundup $\mathrm{WG}^{\circledR}$ ) e sal potássico (Zapp Qi).

No cultivo de soja transgênica, o glyphosate pode ser aplicado em pré-semeadura (dessecação) e/ou em pós-emergência da cultura, flexibilizando as práticas de controle químico de plantas daninhas. As formulações de glyphosate e possiveis épocas de aplicação podem modificar a eficiência de controle das plantas daninhas e a seletividade do herbicida à cultura.

Diferenças na formulação do herbicida podem alterar a absorção e a translocação do ingrediente ativo nas plantas, influenciando a eficiência de controle de plantas daninhas. Segundo Jakelaitis et al. (2001), para o controle de Digitaria horizontalis, as formulações de glyphosate sal de isopropilamina e sal potássico apresentaram maior controle da espécie, comparativamente à formulação de sal amônio. Resultado semelhante foi observado para Brachiaria decumbens, cuja aplicação das formulações de glyphosate sal de isopropilamina e sal potássico promoveu maior controle comparativamente ao glyphosate sal de amônio (Werlang et al., 2003).

Outro fator que pode influenciar o controle de plantas daninhas e a seletividade à cultura é a época de aplicação do glyphosate. Aplicações em estádio inicial podem proporcionar reinfestação das plantas daninhas, enquanto a aplicação em estádio avançado de desenvolvimento reduz o controle de espécies infestantes e permite a competição de plantas daninhas com a cultura no início de seu ciclo. Mulugueta \& Boerboom (2000) verificaram que a aplicação do glyphosate nos estádios vegetativos da soja $\left(\mathrm{V}_{2}\right.$ e $\left.\mathrm{V}_{4}\right)$ proporcionou maior produtividade à cultura, em comparação à aplicação nos estádios reprodutivos $\left(R_{1}\right.$ e $\left.R_{4}\right)$. Entretanto, para o cultivar de soja Pioneer 9831, Norsworthy (2004) constatou baixa variação da produtividade de grãos quando aplicou o glyphosate nos estádios $\mathrm{V}_{2}, \mathrm{~V}_{4}$ e $\mathrm{R}_{2}$ da soja, tanto em aspersões únicas quanto em sequenciais.

De acordo com Reddy \& Zablatowing (2003), a soja resistente ao glyphosate pode sofrer injúrias ocasionadas pelo herbicida sob determinadas condições e formulações do sal de glyphosate utilizado no controle das plantas daninhas. Contudo, são escassos os trabalhos que relatam a ocorrência de reduções na produtividade de grãos de soja resistente ao glyphosate em decorrência da aplicação desse herbicida em pós-emergência da cultura (Grey \& Raymer, 2002; Reddy \& Zablatowing, 2003; Correia \& Durigan, 2007).

O Roundup Ready ${ }^{\circledR}$ é o único herbicida à base de glyphosate, derivado do sal de isopropilamina, que tem registro no Brasil para aplicação em soja transgênica (Correia \& Durigan, 2007). Segundo esses autores, mesmo não possuindo registro, todos os outros produtos comerciais à base de glyphosate estão sendo utilizados em soja transgênica, nas diferentes regiões produtoras do Brasil. Nesse sentido, há necessidade de mais informações sobre 
possiveis efeitos fitotóxicos desses herbicidas na cultura da soja.

Objetivou-se com o trabalho avaliar a seletividade e os componentes da produtividade de grãos de cultivares de soja transgênica e o controle de plantas daninhas, em função de épocas de aplicação e formulações do herbicida glyphosate.

\section{MATERIAL E MÉTODOS}

O experimento foi conduzido na área experimental do Centro Agropecuário da Palma (CAP), da Universidade Federal de Pelotas (UFPel), município de Capão do LeãoRS, durante a estação de crescimento 2005/ 06. O solo da área experimental é classificado como Planossolo Hidromórfico Eutrófico solódico, pertencente à Unidade de Mapeamento Pelotas (Embrapa, 2006). O experimento foi conduzido pelo sistema convencional, sendo a correção do $\mathrm{pH}$ e a adubação de manutenção realizadas conforme análise físico-química do solo, em que: $\mathrm{pH}$ (água) $=6,0$; matéria orgânica $=1,8 \% ; \mathrm{P}=5,5 \mathrm{mg} \mathrm{dm}^{-3} ; \mathrm{K}=20 \mathrm{mg} \mathrm{dm}^{-3}$; $\mathrm{Ca}^{+2}=2,6 \mathrm{cmol}_{\mathrm{c}} \mathrm{dm}^{-3} ; \mathrm{Mg}^{+2}=1 \mathrm{cmol}_{\mathrm{c}} \mathrm{dm}^{-3} ;$ $\mathrm{Al}^{+3}=0,2 \mathrm{cmol}_{\mathrm{c}} \mathrm{dm}^{-3} ; \mathrm{H}+\mathrm{Al}=2,5 \mathrm{cmol}_{\mathrm{c}} \mathrm{dm}^{-3}$; $\mathrm{CTC}_{\text {efetiva }}=3,9 \mathrm{cmol}_{\mathrm{c}} \mathrm{dm}^{-3}$.

O delineamento experimental utilizado foi de blocos completos ao acaso, arranjados em parcelas subsubdivididas, com quatro repetições. As unidades experimentais foram constituídas por parcelas de $90,0 \mathrm{~m}^{2}(45,0 \mathrm{x}$ $2 \mathrm{~m})$, subparcelas de $30,0 \mathrm{~m}^{2}(15,0 \times 2,0 \mathrm{~m})$ e subsubparcelas de $6,0 \mathrm{~m}^{2}(3,0 \times 2,0 \mathrm{~m})$. A soja foi semeada na população de 40 sementes viáveis $\mathrm{m}^{-2}$, em espaçamento entre linhas de $0,4 \mathrm{~m}$, o que proporcionou uma população média de 400.000 plantas ha ${ }^{-1}$. Os cultivares de soja [BRS 244RR, MSOY 7979RR e não registrada (NR)] foram alocados nas parcelas; as épocas de aplicação dos herbicidas (20, 35 e 50 dias após a emergência - DAE), nas subparcelas; e nas subsubparcelas, as formulações de glyphosate (sal de isopropilamina Roundup Ready ${ }^{\circledR}$ e Roundup Transorb ${ }^{\circledR}$, sal de amônio - Roundup $\mathrm{WG}^{\circledR}$ e sal potássico - Zapp $\left.\mathrm{Qi}^{\circledR}\right)$ na dose de 720 g e.a. ha ${ }^{-1}$ e testemunha infestada (sem aplicação).

A aplicação dos herbicidas foi feita utilizando-se pulverizador costal de precisão, pressurizado a $\mathrm{CO}_{2}$, equipado com cinco bicos de pulverização tipo leque Teejet 110.02, mantendo-se pressão constante de $210 \mathrm{kPa}$ e velocidade de deslocamento de $3,6 \mathrm{~km} \mathrm{~h}^{-1}$, calibrado para aspergir um volume de calda herbicida de $150 \mathrm{~L} \mathrm{ha}^{-1}$. A área experimental estava infestada nas épocas de aplicação dos herbicidas por beldroega (Portulaca oleracea), caruru (Amaranthus spp.), papuã (Brachiaria plantaginea), capim-arroz (Echinochloa spp.) e grama-seda (Cynodon dactylon), em população de 48, 31, 27, 80 e 104 plantas $\mathrm{m}^{-2}$, respectivamente.

As condições ambientais médias locais, nas três épocas em que foram aplicados os herbicidas (20, 35 e $50 \mathrm{DAE})$, foram, respectivamente: temperaturas do ar de 23,2, 24,1 e $22,6^{\circ} \mathrm{C}$, UR de 85, 87 e $90 \%$; e ventos de 2,2, 2,6 e 3,0 $\mathrm{km} \mathrm{h}^{-1}$. Nas aplicações das formulações de glyphosate o solo estava superficialmente seco e a temperatura era de $2,0,23,5$ e $24,5^{\circ} \mathrm{C}$ para a primeira, segunda e terceira épocas de aplicação, respectivamente; em ambas, mediu-se a temperatura na profundidade de $5,0 \mathrm{~cm}$. Todas as variáveis atmosféricas foram obtidas na área experimental.

As variáveis avaliadas foram fitotoxicidade dos herbicidas aos cultivares de soja aos sete dias após a aplicação dos tratamentos (DAT), controle das plantas daninhas aos 14 e 28 DAT, número de vagens e grãos por planta, peso de mil grãos e produtividade de grãos. As avaliações de fitotoxicidade e controle foram realizadas visualmente, utilizando-se escala percentual, em que 0 (zero) e $100 \%$ (cem) corresponderam a nenhum controle das espécies infestantes ou dano à cultura e morte das plantas daninhas ou da cultura, respectivamente. O número de vagens e o de grãos por planta foram determinados pela contagem em cinco plantas na subsubparcela. Para determinar o peso de mil grãos, foram utilizadas quatro subamostras de cem grãos da subsubparcela, sendo a umidade de grãos corrigida para 13\%. A produtividade de grãos foi determinada pela colheita das três fileiras centrais de cada subsubparcela, sendo os grãos pesados e corrigidos para $13 \%$ de umidade.

Os dados obtidos foram analisados quanto à sua homogeneidade e normalidade; atendendo a essas premissas, foram posteriormente submetidos à análise de variância. Os efeitos 
de cultivares, época de aplicação e formulações herbicidas foram avaliados pelo teste de Tukey $(p \leq 0,05)$. Na elaboração das análises estatísticas foi utilizado o programa Winstat (2002-Versão 2.1.) (Machado et al., 2002).

\section{RESULTADOS E DISCUSSÃO}

Para a variável fitotoxicidade aos cultivares de soja aos 7 DAT, não se verificou interação dos fatores, havendo efeito de época de aplicação e formulações de glyphosate (Tabela 1). A fitotoxicidade foi baixa, sendo maior nas primeiras épocas de aplicação, quando comparada aos $50 \mathrm{DAE}$.

$\mathrm{Na}$ comparação entre formulações do herbicida glyphosate, apenas o sal de amônio (Roundup $\mathrm{WG}^{\circledR}$ ) causou fitotoxicidade superior à da testemunha infestada (Tabela 2). Resultados semelhantes foram observados pela aplicação de sais de isopropilamina, os quais causaram baixa injúria às plantas de soja (Reddy \& Zablotowics, 2003). O herbicida glyphosate, comparado aos outros, foi o que

Tabela 1 - Fitotoxicidade média a três genótipos de soja e quatro formulações de glyphosate em função da época de aplicação do herbicida. Capão do Leão-RS, 2005/06

\begin{tabular}{|c|c|}
\hline Época de aplicação $\left(\mathrm{DAE}^{1 /}\right)$ & Fitotoxicidade (\%) 7 $\mathrm{DAT}^{2 /}$ \\
\hline 20 & $0,5 \mathrm{a}^{\frac{3}{}}$ \\
\hline 35 & $0,3 \mathrm{a}$ \\
\hline 50 & $0,0 \mathrm{~b}$ \\
\hline
\end{tabular}

${ }^{1 /}$ Dias após a emergência; ${ }^{2 /}$ Dias após a aplicação dos tratamentos; ${ }^{3} /$ Médias seguidas da mesma letra na coluna não diferem entre si pelo teste de Tukey $(\mathrm{p} \leq 0,05)$.

Tabela 2 - Fitotoxicidade média a três genótipos de soja e três épocas de aplicação em função da formulação do herbicida. Capão do Leão-RS, 2005/06

\begin{tabular}{|l|c|}
\hline \multicolumn{1}{|c|}{ Formulação de glyphosate } & Fitotoxicidade (\%) 7 DAT $^{\underline{1}}$ \\
\hline Testemunha infestada & $0,0 \mathrm{~b}^{\underline{2}}$ \\
\hline Roundup Ready $^{\circledR}$ & $0,1 \mathrm{~B}$ \\
\hline Roundup WG $^{\circledR}$ & $0,4 \mathrm{~A}$ \\
\hline Roundup Transorb & $0,3 \mathrm{Ab}$ \\
\hline Zapp Qi $^{\circledR}$ & $0,3 \mathrm{Ab}$ \\
\hline
\end{tabular}

1/ Dias após a aplicação dos tratamentos; ${ }^{2}$ Médias seguidas da mesma letra na coluna não diferem entre si pelo teste de Tukey $(\mathrm{p} \leq 0,05)$. proporcionou menores injúrias, confirmando sua elevada seletividade à soja RR (Johnson et al., 2002).

Aos 14 DAT não se verificou qualquer efeito de fitotoxicidade das formulações de glyphosate à cultura (dados não apresentados). De maneira semelhante, Correia \& Durigan (2007), ao aplicarem diferentes formulações de glyphosate em única época, não observaram injúrias sobre duas variedades de soja transgênica.

Não houve interação entre os fatores testados para o controle de plantas daninhas. Contudo, verificou-se interação de épocas de aplicação e formulações do herbicida glyphosate (Tabela 3). A comparação entre formulações de glyphosate, dentro de cada época de aplicação, demonstrou, para todas as espécies daninhas e épocas de avaliação, aos 20 e $35 \mathrm{DAE}$, controle superior a 95\%. Esse resultado é decorrente da alta eficácia do herbicida glyphosate em aplicações iniciais, independentemente do sal utilizado na formulação. Os resultados condizem com os observados por Reddy \& Zablotowics (2003) para Echinochloa crus-galli, Ipomoea lacunose, Amaranthus hybridus e Cyperus esculentus, em que foi observado elevado controle de plantas daninhas, independentemente da formulação utilizada.

Aos 50 DAE, verificou-se redução na eficiência de controle das plantas daninhas, $o$ que pode decorrer do estádio avançado de seu desenvolvimento no momento da aplicação e, também, do efeito "guarda-chuva" da cultura sobre as espécies. A formulação de sal de amônio (Roundup $\mathrm{WG}^{\circledR}$ ) foi a que apresentou maior eficiência de controle das plantas daninhas em todas as épocas de aplicação. Estes resultados diferem dos observados por Werlang et al. (2003) para Brachiaria decumbens, em que a formulação Roundup $\mathrm{WG}^{\circledR}$ foi a que apresentou menor nivel de controle.

Comparando as três formulações de glyphosate entre as épocas de aplicação, observou-se redução na eficácia de controle dos três sais de glyphosate na última época de aplicação, em comparação às aspersões realizadas aos 20 e 35 DAE. Esses resultados podem ter ocorrido em função do estádio avançado em que as espécies infestantes se encontravam 
Tabela 3 - Controle de beldroega (Portulaca oleracea), caruru (Amaranthus spp.), papuã (Brachiaria plantaginea), capim-arroz (Echinochloa spp.) e grama-seda (Cynodon dactylon) em função de época de aplicação e formulação do herbicida glyphosate. Capão do Leão-RS, 2005/06

\begin{tabular}{|c|c|c|c|c|c|c|c|c|c|c|c|}
\hline \multirow{3}{*}{$\begin{array}{c}\text { Época de } \\
\text { aplicação } \\
\left(\mathrm{DAE}^{1 /}\right)\end{array}$} & \multirow{3}{*}{$\begin{array}{c}\text { Formulação de } \\
\text { glyphosate }\end{array}$} & \multicolumn{10}{|c|}{ Controle (\%) } \\
\hline & & \multicolumn{2}{|c|}{ Beldroega } & \multicolumn{2}{|c|}{ Caruru } & \multicolumn{2}{|c|}{$\begin{array}{l}\text { Papuã/capim- } \\
\text { marmelada }\end{array}$} & \multicolumn{2}{|c|}{ Capim-arroz } & \multicolumn{2}{|c|}{ Grama-seda } \\
\hline & & $14 \mathrm{DAT}^{2} /$ & $28 \mathrm{DAT}$ & 14 DAT & $28 \mathrm{DAT}$ & 14 DAT & 28 DAT & 14 DAT & $28 \mathrm{DAT}$ & 14 DAT & $28 \mathrm{DAT}$ \\
\hline \multirow{5}{*}{20} & Testemunha infestada & $0 \mathrm{Ab}^{3 /}$ & $0 \mathrm{Ab}$ & $0 \mathrm{Ab}$ & $\overline{0 \mathrm{Ab}}$ & $0 \mathrm{Ab}$ & $0 \mathrm{Ac}$ & $0 \mathrm{Ab}$ & $0 \mathrm{Ab}$ & $0 \mathrm{Ab}$ & $0 \mathrm{Ab}$ \\
\hline & Roundup Ready $^{\circledR}$ & $99 \mathrm{Aa}$ & $96 \mathrm{Aa}$ & $100 \mathrm{Aa}$ & $99 \mathrm{Ba}$ & $100 \mathrm{Aa}$ & $99 \mathrm{Ba}$ & $100 \mathrm{Aa}$ & $98 \mathrm{ABa}$ & $99 \mathrm{Aa}$ & $98 \mathrm{Aa}$ \\
\hline & Roundup WG $^{\circledR}$ & $98 \mathrm{Aa}$ & $96 \mathrm{Aa}$ & $100 \mathrm{Aa}$ & $99 \mathrm{Ba}$ & $100 \mathrm{Aa}$ & $98 \mathrm{Bab}$ & $99 \mathrm{Aa}$ & $97 \mathrm{Aa}$ & $99 \mathrm{Aa}$ & $98 \mathrm{Aa}$ \\
\hline & Roundup Transorb $^{\circledR}$ & $99 \mathrm{Aa}$ & $96 \mathrm{Aa}$ & $100 \mathrm{Aa}$ & $99 \mathrm{Ba}$ & $100 \mathrm{Aa}$ & $98 \mathrm{Bab}$ & $100 \mathrm{Aa}$ & $97 \mathrm{Aa}$ & $97 \mathrm{Aa}$ & $97 \mathrm{Aa}$ \\
\hline & Zapp QI ${ }^{\circledR}$ & $98 \mathrm{Aa}$ & $95 \mathrm{Aa}$ & $100 \mathrm{Aa}$ & $98 \mathrm{Ba}$ & $99 \mathrm{ABa}$ & $97 \mathrm{Bb}$ & $99 \mathrm{Aa}$ & $96 \mathrm{Aa}$ & $96 \mathrm{Aa}$ & $96 \mathrm{Aa}$ \\
\hline \multirow{5}{*}{35} & Testemunha infestada & $0 \mathrm{Ab}$ & $0 \mathrm{Ab}$ & $0 \mathrm{Ab}$ & $0 \mathrm{Ab}$ & $0 \mathrm{Ab}$ & $0 \mathrm{Ab}$ & $0 \mathrm{Ab}$ & $0 \mathrm{Ab}$ & $0 \mathrm{Ab}$ & $0 \mathrm{Ab}$ \\
\hline & Roundup Ready $^{\circledR}$ & $100 \mathrm{Aa}$ & $99 \mathrm{Aa}$ & $100 \mathrm{Aa}$ & $100 \mathrm{Aa}$ & $100 \mathrm{Aa}$ & $100 \mathrm{Aa}$ & $100 \mathrm{Aa}$ & $100 \mathrm{Aa}$ & $99 \mathrm{Aa}$ & $99 \mathrm{Aa}$ \\
\hline & Roundup WG $^{\mathbb{B}}$ & $99 \mathrm{Aa}$ & $99 \mathrm{Aa}$ & $100 \mathrm{Aa}$ & $100 \mathrm{Aa}$ & $100 \mathrm{Aa}$ & $100 \mathrm{Aa}$ & $100 \mathrm{Aa}$ & $100 \mathrm{Aa}$ & $99 \mathrm{Aa}$ & $98 \mathrm{Aa}$ \\
\hline & Roundup Transorb $^{\circledR}$ & $99 \mathrm{Aa}$ & $99 \mathrm{Aa}$ & $100 \mathrm{Aa}$ & $100 \mathrm{Aa}$ & $100 \mathrm{Aa}$ & $100 \mathrm{Aa}$ & $99 \mathrm{Aa}$ & $100 \mathrm{Aa}$ & $96 \mathrm{Aa}$ & $97 \mathrm{Aa}$ \\
\hline & Zapp QI ${ }^{\circledR}$ & $99 \mathrm{Aa}$ & $99 \mathrm{Aa}$ & $100 \mathrm{Aa}$ & $100 \mathrm{Aa}$ & $100 \mathrm{Aa}$ & $100 \mathrm{Aa}$ & $100 \mathrm{Aa}$ & $100 \mathrm{Aa}$ & $97 \mathrm{Aa}$ & $98 \mathrm{Aa}$ \\
\hline \multirow{5}{*}{50} & Testemunha infestada & $0 \mathrm{Ad}$ & $0 \mathrm{Ad}$ & $0 \mathrm{Ab}$ & $0 \mathrm{Ab}$ & $0 \mathrm{Ac}$ & $0 \mathrm{Ab}$ & $0 \mathrm{Ab}$ & $0 \mathrm{Ac}$ & $0 \mathrm{Ac}$ & $0 \mathrm{Ac}$ \\
\hline & Roundup Ready $^{(B)}$ & $80 \mathrm{Bab}$ & $87 \mathrm{Ba}$ & $100 \mathrm{Aa}$ & $100 \mathrm{Aa}$ & $99 \mathrm{Aa}$ & $100 \mathrm{Aa}$ & $93 \mathrm{Aa}$ & $95 \mathrm{Bb}$ & $89 \mathrm{Ba}$ & $93 \mathrm{Aa}$ \\
\hline & Roundup $\mathrm{WG}^{\circledR}$ & $86 \mathrm{Ba}$ & $93 \mathrm{Aa}$ & $100 \mathrm{Aa}$ & $100 \mathrm{Aa}$ & $99 \mathrm{Aa}$ & $100 \mathrm{Aa}$ & $96 \mathrm{Aa}$ & $100 \mathrm{Aa}$ & $95 \mathrm{Aa}$ & $98 \mathrm{Aa}$ \\
\hline & Roundup Transorb $^{\circledR}$ & $65 \mathrm{Bc}$ & $71 \mathrm{Bc}$ & $96 \mathrm{Aa}$ & $100 \mathrm{Aa}$ & $98 \mathrm{Bb}$ & $100 \mathrm{Aa}$ & $87 \mathrm{Ba}$ & $92 \mathrm{Bb}$ & $79 \mathrm{Bb}$ & $81 \mathrm{Bb}$ \\
\hline & Zapp QI ${ }^{\circledR}$ & $74 \mathrm{Bb}$ & $79 \mathrm{Bb}$ & $100 \mathrm{Aa}$ & $100 \mathrm{Aa}$ & $98 \mathrm{Bab}$ & $100 \mathrm{Aa}$ & $87 \mathrm{Ba}$ & $92 \mathrm{Bb}$ & $80 \mathrm{Bb}$ & $88 \mathrm{Aab}$ \\
\hline
\end{tabular}

1/ Dias após a emergência; ${ }^{2}$ Dias após a aplicação dos tratamentos; ํㅜㄹédias seguidas por letras maiúsculas idênticas, na coluna, comparando épocas de aplicação dentro de cada formulação de glyphosate, e minúsculas idênticas, na coluna, comparando formulação de glyphosate dentro de cada época de aplicação, não diferiram pelo teste de Tukey $(\mathrm{p} \leq 0,05)$.

ou do efeito "guarda-chuva" da cultura sobre as plantas daninhas, conforme descrito anteriormente (Tabela 3). Entretanto, segundo Norsworthy \& Oliver (2002), o controle de Ipomoea lacunosa e Sesbania exaltata aumentou com a aplicação em estádio vegetativo $V_{4}$, comparativamente ao $\mathrm{V}_{2}$.

Quanto à variável número de vagens por planta, verificou-se efeito da interação dos fatores cultivares e formulações de glyphosate e efeito isolado de época de aplicação (Tabelas 4 e 5). A comparação entre as formulações do herbicida glyphosate demonstrou resposta diferenciada em função dos cultivares de soja. Entre cultivares, observou-se que o NR, em geral, foi o que apresentou maior produção de vagens por planta na aplicação do sal de isopropilamina (Roundup Ready ${ }^{\circledR}$ ) e sal potássico (Zapp Qi ${ }^{\circledR}$ ) (Tabela 4). Já para os demais tratamentos herbicidas ou na testemunha infestada não se observaram diferenças. $O$ número de vagens por planta foi superior na última época de aplicação, comparativamente às demais épocas (Tabela 5).

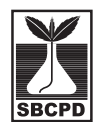

Não se verificou interação dos fatores testados para a variável número de grãos por planta, havendo apenas efeito de formulações de glyphosate (Tabela 6). A aplicação do herbicida glyphosate, independentemente da formulação, proporcionou maior número de grãos por planta, em relação à testemunha, porém não se observaram diferenças entre formulações. Esses resultados podem decorrer da elevada eficiência de controle de plantas daninhas obtida pela aplicação das formulações do herbicida glyphosate (Tabela 3).

O peso de mil grãos não apresentou interação entre os fatores testados, apenas efeito de cultivares (Tabela 7). Entre os cultivares estudados, o que apresentou maior peso de grão foi o NR, o que pode ser decorrente do seu potencial genético.

A produtividade de grãos não mostrou interação entre os fatores testados, sendo observados efeitos independentes de época de aplicação, cultivares e formulações de glyphosate (Tabelas 8, 9 e 10). A produtividade foi superior quando a aplicação foi realizada aos 35 e 50 DAE, comparativamente a $20 \mathrm{DAE}$ 
(Tabela 8). Isso pode ser consequência da competição exercida pelas plantas daninhas que emergiram após a aplicação do herbicida, na fase inicial de desenvolvimento da cultura, uma vez que o glyphosate não apresenta efeito residual (Vencill, 2002). Em estudos para avaliação do período crítico de competição de plantas daninhas com a cultura da soja, Mulugueta \& Boerboom (2000) verificaram perdas de produtividade somente a partir dos 50 DAE. Resultados semelhantes foram observados por Norsworthy (2004), em que se observou baixa variação da produtividade em relação às diferentes épocas de aplicação do herbicida glyphosate.

Com relação aos cultivares de soja, o BRS 244RR foi o que apresentou menor produtividade de grãos, comparativamente aos demais (Tabela 9). Esses resultados podem ser devido ao potencial genético do cultivar ou à menor adaptação às condições edafoclimáticas da região. Resultados semelhantes a esses foram observados por Correia \& Durigan (2007), ao detectarem diferenças na produtividade de grãos dos cultivares de soja M-SOY 8008RR e CD 214RR, submetidos a aplicações de diferentes formulações de glyphosate em única época de aplicação. Esses autores também atribuem esse fato a diferenças genéticas entre os cultivares e não a influências relacionadas ao uso de herbicidas à base de glyphosate.

Não se verificou diferença na produtividade de grãos de soja entre as formulações do herbicida glyphosate, porém em todas ela foi superior à da testemunha infestada (Tabela 10). Esses resultados condizem, em parte, com os observados para a variável número de vagens por planta (Tabela 5) e para a variável número de grãos por planta (Tabela 6). Em trabalho realizado por Reddy \& Zablotowics (2003), foram observados resultados semelhantes, onde a aplicação de glyphosate nas formulações de sal de isopropilamina ou sal de amônio não causou reduções na produtividade da cultura. Nesse mesmo sentido, Correia \& Durigan (2007) afirmam que as diferenças na produtividade de variedades de soja RR ocorrem em função de características genéticas diferenciadas de cada variedade e não do uso de diferentes formulações de glyphosate, como já exposto anteriormente.
Tabela 4 - Número de vagens por planta em função de cultivares e formulações do herbicida glyphosate. Capão do Leão-RS, 2005/06

\begin{tabular}{|l|c|c|c|}
\hline \multirow{2}{*}{$\begin{array}{c}\text { Formulação de } \\
\text { glyphosate }\end{array}$} & \multicolumn{3}{|c|}{ Cultivar } \\
\cline { 2 - 4 } & BRS 244RR & $\begin{array}{c}\text { MSOY } \\
7979 R R\end{array}$ & Não registrada \\
\hline Testemunha infestada & $46 \mathrm{~b} \mathrm{~A} \mathrm{~A}^{\underline{\prime}}$ & $43 \mathrm{~b} \mathrm{~A}$ & $46 \mathrm{c} \mathrm{A}$ \\
\hline Roundup Ready $^{\circledR}$ & $57 \mathrm{a} \mathrm{bB}$ & $70 \mathrm{a} \mathrm{AB}$ & $85 \mathrm{a} \mathrm{A}$ \\
\hline Roundup WG $^{\circledR}$ & $73 \mathrm{a} \mathrm{A}$ & $66 \mathrm{a} \mathrm{A}$ & $63 \mathrm{~b} \mathrm{cA}$ \\
\hline Roundup Transorb $^{\circledR}$ & $55 \mathrm{~b} \mathrm{~A}$ & $67 \mathrm{a} \mathrm{A}$ & $73 \mathrm{a} \mathrm{bA}$ \\
\hline Zapp QI $^{\circledR}$ & $53 \mathrm{~b} \mathrm{~B}$ & $65 \mathrm{a} \mathrm{B}$ & $85 \mathrm{a} \mathrm{A}$ \\
\hline
\end{tabular}

1/ Médias seguidas pela mesma letra minúscula, nas colunas, comparando as formulações de glyphosate em cada cultivar, e maiúscula, nas linhas, comparando os cultivares para cada formulação de glyphosate, não diferem entre si pelo teste de Tukey $(\mathrm{p} \leq 0,05)$.

Tabela 5 - Número de vagens por planta em função de época de aplicação de glyphosate. Capão do Leão-RS, 2005/06

\begin{tabular}{|c|c|}
\hline Época de aplicação (DAE) $^{1 /}$ & Número de vagens por planta \\
\hline 20 & $61 \mathrm{~B}^{\underline{2} /}$ \\
\hline 35 & $60 \mathrm{~b}$ \\
\hline 50 & $69 \mathrm{a}$ \\
\hline
\end{tabular}

${ }^{1 /}$ Dias após a emergência; ${ }^{2 /}$ Médias seguidas da mesma letra na coluna não diferem entre si pelo teste de Tukey $(p \leq 0,05)$.

Tabela 6 - Número de grãos por planta em função de formulações do herbicida glyphosate. Capão do Leão-RS, 2005/06

\begin{tabular}{|l|c|}
\hline \multicolumn{1}{|c|}{ Formulação de glyphosate } & Número de grãos por planta \\
\hline Testemunha & $64 \mathrm{~b}^{{ }^{1 /}}$ \\
\hline Roundup Ready $^{\circledR}$ & $106 \mathrm{a}$ \\
\hline Roundup WG $^{\circledR}$ & $101 \mathrm{a}$ \\
\hline Roundup Transorb $^{\circledR}$ & $98 \mathrm{a}$ \\
\hline Zapp QI & $97 \mathrm{a}$ \\
\hline
\end{tabular}

${ }^{1 /}$ Médias seguidas da mesma letra na coluna não diferem entre si pelo teste de Tukey $(\mathrm{p} \leq 0,05)$

Tabela 7 - Peso de mil grãos de soja em função de cultivares. Capão do Leão-RS, 2005/06

\begin{tabular}{|l|c|}
\hline \multicolumn{1}{|c|}{ Cultivar } & Peso de mil grãos (g) \\
\hline BRS 244RR & $200,29 \mathrm{~b}^{1 /}$ \\
\hline MSOY 7979RR & $200,36 \mathrm{~b}$ \\
\hline Genótipo não registrado & $206,42 \mathrm{a}$ \\
\hline
\end{tabular}

${ }^{1 /}$ Médias seguidas da mesma letra na coluna não diferem entre si pelo teste de Tukey $(\mathrm{p} \leq 0,05)$. 
Tabela 8 - Produtividade de grãos de soja em função da época de aplicação do herbicida glyphosate. Capão do Leão-RS, 2005/06

\begin{tabular}{|c|c|}
\hline Época de aplicação (DAE) $)^{\frac{1}{1}}$ & Produtividade $\left(\mathrm{kg} \mathrm{h}^{-1}\right)$ \\
\hline 20 & $3.033 \mathrm{~b}^{2 /}$ \\
\hline 35 & $3.441 \mathrm{a}$ \\
\hline 50 & $3.456 \mathrm{a}$ \\
\hline
\end{tabular}

1/ Dias após a emergência; $\underline{2} /$ Médias seguidas da mesma letra na coluna não diferem entre si pelo teste de Tukey $(\mathrm{p} \leq 0,05)$.

Tabela 9 - Produtividade de grãos de soja em função de cultivares. Capão do Leão-RS, 2005/06

\begin{tabular}{|l|c|}
\hline \multicolumn{1}{|c|}{ Cultivar } & Produtividade $\left(\mathrm{kg} \mathrm{ha}^{-1}\right)$ \\
\hline BRS 244RR & $2.834 \mathrm{~b}^{1 /}$ \\
\hline MSOY 7979RR & $3.528 \mathrm{a}$ \\
\hline Genótipo não registrado & $3.568 \mathrm{a}$ \\
\hline
\end{tabular}

${ }_{1 /}$ Médias seguidas da mesma letra na coluna não diferem entre si pelo teste de Tukey $(\mathrm{p} \leq 0,05)$.

Tabela 10 - Produtividade de grãos de soja em função de formulações do herbicida glyphosate. CAP/UFPel, Capão do Leão-RS, 2005/06

\begin{tabular}{|l|c|}
\hline \multicolumn{1}{|c|}{ Formulação de glyphosate } & Produtividade $\left(\mathrm{kg} \mathrm{ha}^{-1}\right)$ \\
\hline Testemunha & $2.381 \mathrm{~b}^{1 /-}$ \\
\hline Roundup Ready $^{\circledR}$ & $3.553 \mathrm{a}$ \\
\hline Roundup WG & $3.581 \mathrm{a}$ \\
\hline Roundup Transorb $^{\circledR}$ & $3.510 \mathrm{a}$ \\
\hline Zapp QI & $3.524 \mathrm{a}$ \\
\hline
\end{tabular}

1/ Médias com letras idênticas na coluna não diferem pelo teste de Tukey $(\mathrm{p} \leq 0,05)$.

Neste trabalho, determinaram-se as épocas de aplicação do glyphosate em função de dias após a emergência (DAE) e não por estádio de desenvolvimento da cultura da soja. Entretanto, essa metodologia pode não ser apropriada, pelo fato de que o estádio fenológico é que define os tratos culturais nas culturas. Contudo, a definição do período de convivência das plantas daninhas pelo estádio fenológico também não é totalmente apropriada, pois leva em consideração apenas um dos componentes do sistema - a cultura, deixando de considerar as espécies daninhas (Vidal et al., 2005). Segundo os autores, a cultura, quando semeada em período frio, pode levar muitos dias para a diferenciação de um estádio fenológico para o outro. Todavia, na comunidade infestante da cultura poderá haver espécies adaptadas a se desenvolverem adequadamente nessas condições, de forma que, quando a cultura estiver no referido estádio de desenvolvimento, as plantas daninhas já terão dominado o nicho, comprometendo seriamente a produtividade de grãos da soja.

Os resultados demonstram que o herbicida glyphosate nas formulações testadas foi seletivo aos cultivares de soja RR. Em geral, a melhor formulação para controle das plantas daninhas beldroega, caruru, papuã, capimarroz e grama-seda foi a Roundup $\mathrm{WG}^{\circledR}$. A aplicação nos estádios iniciais de desenvolvimento da cultura proporcionou melhor controle das plantas daninhas. A produtividade de grãos variou entre cultivares de soja, não diferiu entre as formulações do herbicida glyphosate e foi superior quando a aplicação foi realizada nos estádios tardios de desenvolvimento da cultura. O cultivar de soja MSOY 7979RR e o genótipo não registrado apresentaram as maiores produtividades de grãos, e o BRS 244RR, a menor, ao se aplicarem as formulações de glyphosate em diferentes épocas.

\section{LITERATURA CITADA}

CORREIA, N. M.; DURIGAN, J. C. Seletividade de diferentes herbicidas à base de glyphosate a soja RR. Planta Daninha, v. 25, n. 2, p. 375-379, 2007.

EMPRESA BRASILEIRA DE PESQUISA AGROPECUÁRIA - EMBRAPA. Centro Nacional de Pesquisa de Solos. Sistema brasileiro de classificação de solos. Rio de Janeiro: 2006. 306 p.

FERREIRA, F. G. et al. Efeito da inundação do solo sobre o crescimento e produção de grãos de duas cultivares de soja. In: CONGRESSO BRASILEIRO DE ARROZ IRRIGADO, 2 ., 2001, Porto Alegre. Anais... Porto Alegre: Instituto Riograndense do Arroz, 2001. p. 823-826.

FRONZA, V.; ZITO, R. K. A revolução da RR. Cultivar, n. 79 , p. 26-28, 2005.

GALON, L. et al. Controle de plantas daninhas e seletividade de herbicidas à cultura da soja, aplicados em dois volumes de calda. R. Bras. Agroci., v. 13, n. 3, p. 325-330, 2007.

GREY, T. L.; RAYMER, P. Sicklepod (Senna obtusifolia) and red Morningglory (Ipomoea cocinea) control in glyphosateresistant soybean with narrow rows and postemergence herbicide mixtures. Weed Technol., v. 16, n. 3, p. 669-674, 2002.

Planta Daninha, Viçosa-MG, v. 27, n. 4, p. 739-746, 2009 
JAKELAITIS, A. et al. Controle de Digitaria horizontalis pelos herbicidas glyphosate, sulfosate e glifosate potássico submetidos a diferentes intervalos de chuva após a aplicação. Planta Daninha, v. 19, n. 2, p. 279-285, 2001.

JOHNSON, B. F. et al. Herbicide effects on visible injury, leaf area, and yield of glyphosate-resistant soybean (Glycine max). Weed Technol., v. 16, n. 3, p. 554-566, 2002.

MACHADO, A. A. et al. Sistema de análises estatísticas para Windows - WINSTAT (Versão 2.11). Pelotas:

Universidade Federal de Pelotas, 2002.

MULUGUETA, D.; BOERBOOM, C. M. Critical time of weed removal in glyphosate-resistant Glycine max. Weed Sci., v. 42, n. 1, p. 35-42, 2000.

NORSWORTHY, J. K. Conventional soybean plant and progeny response to glyphosate. Weed Technol., v. 18, n. 3, p. $527-531,2004$

NORSWORTHY, J. K.; OLIVER, L. R. Effect of irrigation, soybean (Glycine max) density, and glyphosate on hemp sesbania (Sesbania exaltata) and pitted morningglory (Ipomoea lacunosa) interference in soybean. Weed Technol., v. 16, n. 1 , p. $7-19,2002$
REDDY, K. N.; ZABLOTOWICZ, R. M. Glyphosateresistant soybean response to various salts of glyphosate and glyphosate accumulation in soybean nodules. Weed Sci., v. 51, n. 4 , p. $496-502,2003$.

RODRIGUES, B. N.; ALMEIDA, F. S. Guia de herbicidas. 5.ed. Londrina: 2005. p. 275-289.

WERLANG, R. C. et al. Efeitos da chuva na eficiência de formulações e doses de glyphosate no controle de Brachiaria decumbens. Planta Daninha, v. 21, n. 1, p. 121-130, 2003.

VENCILL, W. K. (Ed.) Herbicide handbook. 4.ed Lawrence: Weed Science Society of America, 2002. $493 \mathrm{p}$.

VIDAL, R. A.; FLECK, N. G.; MEROTTO JR., A. Período anterior ao dano no rendimento econômico (PADRE): nova abordagem sobre os períodos de interferência entre plantas daninhas e cultivadas. Planta Daninha, v. 23, n. 3, p. $387-396,2005$. 